\title{
Cavaleiro do Destino: a experiência prática do artista-docente no PIBID-TEATRO- UFMA
}

\author{
Eixo temático: Formação de professores em Teatro
}

\section{Resumo}

A experiência prática do artista-docente no PIBID-TEATRO-UFMA. Visa-se tecer reflexões acerca dos 04 meses de processo de montagem do espetáculo "O cavaleiro do Destino”, com o grupo de Teatro do Centro de Ensino Médio Liceu Maranhense no contexto do Programa de Iniciação à Docência (PIBID). Objetiva-se avaliar os processos através dos seguintes instrumentos pedagógicos: protocolos dos alunos-atores; registros de imagem e vídeo; planos de aulas e suas funcionalidades; prática diretor-pedagogo do artista-docente. Salientam-se as noções de prática teatral como eixo de ensino, aspectos pedagógicos da experiência teatral, jogo teatral, artista docente, metodologia do ensino de teatro, ensino não formal, teatro e cidadania, teatro na escola, dentre outros. Subsidiam as análises e discussões dos resultados a Lei de Diretrizes e Bases e PCN's, além de autores como Santana (2009), Desgranges (2006), Teles (2013) Pupo, Koudela (2001), Almeida (2009), Ghon (2015), Moraes (2011). Pontua-se a importância da experiência estético-artística como ponto fulcral de domínio da prática docente, com fins de romper com o distanciamento existente entre professor e artista e dar lugar a um profissional híbrido, dotado de capacidades amplas para suplantar os desafios inerentes à prática escolar.

Palavras-chave: PIBID. Artista-docente. Formação de professores (a). Teatro na Escola. Ensino não formal.

\begin{abstract}
The practical experience of the artist-teacher in PIBID-TEATRO-UFMA. This article relies on four months of assembly process of the show "The Knight of Destiny", by the group Teatro do Centro de Ensino Médio Liceu Maranhense, based on a PIBID (Programa de Iniciação à Docênci) program. The main goal is to evaluate the processes through the following pedagogical instruments: student-actor protocols; image and video records; classes' plans and their functionalities; practical director-pedagogue of the artist/teacher. The notions of theatrical practice as teaching axis, pedagogical aspects of theatrical experience, theater play, teacher artist, theater teaching methodology, non-formal teaching, theater and citizenship,
\end{abstract}


theater in school, among others are highlighted. This article is a result of deep reflection on the results of the "Law of Guidelines and Bases and PCNs" and on authors such as Santana (2009), Desgranges (2006), Teles (2013) Pupo, Koudela (2001), Almeida, Moraes (2011). The importance of aesthetic-artistic experience is emphasized as the main point of hold the teaching practice, in order to break away from the gap between teacher and artist and give place to a hybrid professional, with ample capacities to overcome the inherent challenges of practice school.

Keywords: PIBID. Teaching Artist. Training Teacher. School theater. Non-formal Teaching

A prática artística na escola ainda é um desafio aos teatro-educadores, tanto quando essas atividades se inserem no contexto da sala regular como quando são executadas como atividades complementares. Estes desafios perpassam por diversas esferas, desde a escola, o professor e os estudantes. O valor pedagógico intrínseco à essas experiências é apontado por Desgranges (2006), que só será alcançado a partir de uma prática “não-escolarizada”, “nãodidatizada”, para que se preserve sua potencialidade.

Pensar este processo se faz relevante no sentido de discutir os caminhos metodológicos encontrados pelos bolsistas-educadores. Trata-se do processo formativo dos acadêmicos de teatro na universidade, ao currículo basilar e às provocações de sua aplicabilidade no contexto escolar, mediante a aplicação do projeto do PIBID-TEATRO-UFMA. O Programa busca subsidiar a formação de professores a partir de uma experiência prática que favoreça o desenvolvimento de habilidades e competências artísticas e pedagógicas e teve como tema “Teatro na Escola: da tradição à contemporaneidade”.

Nos 04 meses de montagem do espetáculo, observou-se aspectos que influenciaram no desenvolvimento da metodologia de trabalho onde o grupo de bolsistas-educadores pensaram o teatro durante todo o processo de ensino e aprendizagem como uma prática catalisadora para emancipação do indivíduo e do ser social, haja vista que “fazer teatro é aprender a jogar [...] 'Jogo é relação', relação com o outro, consigo mesmo e com o meio ambiente à sua volta.” (SOARES, 2010, p. 53).

Como resultados, reitera-se as considerações de Santana (2010) sobre os aspectos práticos da formação docente, vistos como especificações das teorias apreendidas em sala de aula, dando- 
lhes a possibilidade de aprofundamento nos saberes construídos a partir da experiência, sem perder de vista sua aplicação pedagógica conforme determina os parâmetros curriculares nacionais, triangulando a prática do fazer, do apreciar e refletir.

As reflexões se expandem para análise de procedimentos pedagógicos durante os processos que foram possíveis, devido aos agentes formadores caracterizarem-se como artistas-docentes inseridos no contexto de ensino básico, assim, defendendo a experiência estético-artística como ponte basilar do processo de formação do licenciado em Teatro e do estudante do ensino básico, “que leva ao saber fazer e o domínio da prática docente”. (SANTANA, 2013, p. 85, grifo do autor).

Por fim, a partir da premissa proposta por Debortoli (2010) que situa o artista-docente em seu sentido mais amplo de busca de possibilidades de criação em sala de aula para enriquecimento do fazer pedagógico, questiona-se o não-rompimento da fissura dialética entre a formação do professor e do artista, compreendendo esse novo contexto de agente formador híbrido que contribui para uma transgressão estética-pedagógica-artística-teatral e, em medida, como isso se dá na prática no espaço escolar, mediante a importância da superação dos desafios encontrados na lida pedagógica cotidiana. 